\title{
Role of Diffusion-Weighted Imaging in the Evaluation of Perianal Fistulae
}

\author{
Deb K. Boruah ${ }^{1} \quad$ Karuna Hazarika ${ }^{1} \quad$ Halimuddin Ahmed ${ }^{1} \quad$ Krishna K. Borah ${ }^{1} \quad$ Samudra Borah ${ }^{1}$ \\ Seema Malakar ${ }^{1}$ Nobojit Hajoari ${ }^{1}$
}

1Department of Radio-Diagnosis, Tezpur Medical College and

Address for correspondence Deb K. Boruah, MD,

Hospital, Tezpur, Assam, India

PDCC-Neuroradiology, MRI Room, Department of Radio-Diagnosis, Tezpur Medical College and Hospital, Tezpur 784 153, Assam, India (e-mail: drdeb_rad@yahoo.co.in).

Indian J Radiol Imaging 2021;31:91-101.

\begin{abstract}
Keywords

- intersphincteric

- magnetic resonance imaging

- perianal fistulae

- transsphincteric

Background Magnetic resonance imaging (MRI) is the imaging modality of choice for evaluating perianal fistulae, due to its ability to show the relationship of perianal fistulae with anal sphincters, fistula extensions, secondary ramifications and associated complications.

Aim To evaluate the role of diffusion-weighted MRI in the evaluation of perianal fistulae.

Settings and Design A hospital-based cross-sectional study.

Materials and Methods The study group composed of 47 patients of perianal fistula. MRI with diffusion-weighted imaging (DWI) was performed with Philips $0.5 \mathrm{~T}$ Ingenia scanner. DWI with different $b$-values $\left(b=50, b=400\right.$, and $\left.b=800 \mathrm{smm}^{2}\right)$ were obtained. The MRI findings were correlated with local clinical examination and or surgical findings.

Statistical Analysis Used Chi-square test, independent samples $t$-test, and receiver operating characteristic curve analysis.

Result Fifty-nine perianal fistulas in 47 patients were included in the study sample. The visibility of perianal fistula on DWI was less than T2-weighted (T2W) and combined DWI-T2W images. Distinctly visualized (visibility score 2 ) perianal fistulas were observed in 47 fistulas (79.6\%) on DWI, 54 (91.5\%) on T2W, and 58 (98.3\%) on DWI-T2W images. The mean of apparent diffusion coefficient (ADC) values of active fistula was $0.972 \pm 0.127$ [SD] $10^{-3} \mathrm{~mm}^{2} / \mathrm{s}$ and inactive was $1.232 \pm 0.185$ [SD] $10^{-3} \mathrm{~mm}^{2} / \mathrm{s}$ with a significant difference $(p$-value $<0.0005)$. A cut-off mean ADC value of $1.105 \times 10^{-3} \mathrm{~mm}^{2} / \mathrm{s}$ was used to differentiate active from the inactive fistula with a sensitivity of $87.5 \%$ and specificity of $73.3 \%$.

Conclusion Combined DWI-T2W evaluation had a better performance in the detection of fistula than DWI or T2W alone. DWI with mean ADC calculation had a good performance in differentiating active from the inactive fistulas.
\end{abstract}

published online May 23, 2021
DOI https://doi.org/

$10.1055 / \mathrm{s}-0041-1729673$ ISSN 0971-3026

\footnotetext{
(C) 2021. Indian Radiological Association

This is an open access article published by Thieme under the terms of the Creative Commons Attribution-NonDerivative-NonCommercial-License, permitting copying and reproduction so long as the original work is given appropriate credit. Contents may not be used for commercial purposes, or adapted, remixed, transformed or built upon. (https://creativecommons.org/licenses/by-nc-nd/4.0/).

Thieme Medical and Scientific Publishers Private Ltd. A-12, Second Floor, Sector -2, NOIDA -201301, India
} 


\section{Introduction}

Fistula in ano (FIA) is increasingly a common condition that causes morbidity with a prevalence of 1 per 10,000 of the population with an underlying cause of anal glandular infection, Crohn's disease, radiotherapy, or secondary malignancy. ${ }^{1,2}$ FIA commonly affects the young adults with male preponderance. ${ }^{1,3,4}$ The perianal fistulae usually result from anal gland obstruction with subsequent infection, associated secondary abscess formation, and its complications. ${ }^{2,4}$

Surgical excision of the fistulous tract is the treatment option for perianal fistulas. ${ }^{5}$ Recurrence of fistula occurs up to 25 to $30 \%$ after surgery, usually due to the infection that escaped during surgery and/or fistula gone untreated. ${ }^{5}$

Preoperative magnetic resonance imaging (MRI) is of utmost importance to completely evaluate the fistulous tract, ramification/secondary tracts, grading of fistula, and associated abscess. MRI is the accurate preoperative imaging for detailed evaluation of perianal fistulae. 6,7

Because of excellent soft-tissue contrast and multiplanar capability of MRI, it is the ideal preoperative imaging of choice for characterizing perianal fistulae over other imaging modalities ${ }^{3}$ like conventional fistulogram, endoanal/endorectal ultrasonography, perianal ultrasonography, and computed tomography fistulography. Preoperative MRI in FIA can impact surgical planning, decreases the rate of recurrence, and alter the surgical outcome of various types of fistulae. ${ }^{7}$

Diffusion-weighted imaging (DWI) provides good contrast between the acute inflammatory process and adjacent normal-appearing tissues. ${ }^{8}$ Various recent literatures showed good sensitivity and specificity of DWI for detection of perianal fistula, assessment of fistulas activity, and its complicating abscesses. ${ }^{8-10}$

DWI with higher $b$-value provides better contrast, more tissue diffusibility, and less T2 shine-through effect. ${ }^{11}$ Increasing $b$-value in DWI is associated with decreased apparent diffusion coefficient $(A D C)$ value, reduction of T2 shine-through effect in perianal fistula and/or associated abscess. Higher $b$-value DWI images provide more conspicuity of the perianal fistula or associated abscess from the surrounding structures. ${ }^{11}$

A study by Mohsen and Osman observed a preoperative accuracy of $97.8 \%$ for detecting and classifying perianal fistulae with combined DWI and T2W sequences. ${ }^{12}$ Cavusoglu et $\mathrm{al}^{13}$ showed a sensitivity of $72-79 \%$ and specificity of $100 \%$ for preoperative detection of perianal fistula with T2W images alone, while combined DWI and T2W sequences showed sensitivity of 96 to $100 \%$ and specificity of $100 \%$. Previously published studies also showed the difference of mean ADC values between the active and inactive fistulas., ${ }^{3,8,12,14}$

The present study was conducted to evaluate the role of diffusion-weighted MRI in the evaluation of perianal fistulae.

\section{Materials and Methods}

After approval from the institutional ethics review committee, a hospital-based cross-sectional study was conducted in a tertiary care hospital of North-Eastern India from June 2019 to March 2020 with review of clinical and cross-sectional imaging data of consecutive 47 patients of perianal fistula. The study group composed of clinically suspected 47 patients of perianal fistula who underwent an MRI scan of pelvis. Informed consent was obtained from patients/guardians before undergoing an MRI scan.

MRI images were reviewed by two experienced radiologists blinded to clinical information and observed for the presence and numbers of visible perianal fistulas, internal openings, secondary ramifications, sphincteric extension, and associated complications like horseshoe fistula or abscess formation. Previously operated for perianal fistula, the patient refused surgical treatment, and completely healed fistula were excluded from the study. The completely healed fistula was defined when no T2-weighted (T2W) hyperintense signal intensity observed in perianal fistula with no contrast enhancement after gadolinium injection.

$A D C$ value measurement of the perianal fistulous tracts was done in different $b$-value DWI images. Comparison between DWI, T2W, and combined DWI-T2W MRI sequences was done. The MRI findings of perianal fistulae were recorded according to the St James's University Hospital Classification and were correlated with clinical and or surgical observations. Finally, the surgical or local clinical examination findings of FIA were considered as reference standard in this study.

\section{MRI Protocols}

All patients were subjected to an MRI scan using the Philips Ingenia 1.5 Tesla machine (the Netherlands). All patients were subjected to an MRI scan of pelvis in a supine position with phased-array surface coil. The MR protocols of various sequences for evaluation of perianal fistula are shown in - Table 1.

\section{MRI Image Interpretation}

The perianal fistula was evaluated on T1W, T2W, DWI, VISTA, and fat-suppressed postcontrast T1W sequences. MRIs were reviewed and evaluated by two radiologists in all patients in consensus. The details of MRI findings of perianal fistula were evaluated for.

- Primary fistula tract: We follow the radiological classification of perianal fistula of St James's University Hospital Classification for defining the primary fistula tract. ${ }^{5}$ Grade 1 is a simple linear intersphincteric fistula. Grade 2 is intersphincteric fistula with abscess or secondary tract formation. Grade 3 having transsphincteric fistula while Grade 4 having transsphincteric fistula with abscess or secondary tract formation within the ischiorectal fossa. Finally Grade 5 includes supralevator and translevator extensions of fistula.

- Internal opening of fistula: The site of the internal opening was determined according to the clock face. The site of internal opening defined as any defect or interruption of anal sphincter which showed high signal intensity in T2W SPAIR, DWI images, or shows enhancement on postcontrast images. 
Table 1 Protocol for MRI imaging in perianal fistula

\begin{tabular}{|c|c|c|c|c|c|c|c|c|}
\hline Parameters & T2W TSE & $\begin{array}{l}\text { Axial T2W } \\
\text { SPAIR }\end{array}$ & $\begin{array}{l}\text { Coronal T2W } \\
\text { SPAIR }\end{array}$ & $\begin{array}{l}\text { T1W } \\
\text { TSE }\end{array}$ & $\begin{array}{l}\text { Sagittal } \\
\text { STIR }\end{array}$ & DWI & VISTA & FS T1W TSE \\
\hline Imaging plane & $\begin{array}{l}\text { Oblique } \\
\text { axial }\end{array}$ & Oblique axial & Oblique coronal & $\begin{array}{l}\text { Oblique } \\
\text { axial }\end{array}$ & Sagittal & $\begin{array}{l}\text { Oblique } \\
\text { axial }\end{array}$ & $\begin{array}{l}\text { Oblique } \\
\text { axial }\end{array}$ & $\begin{array}{l}\text { Oblique axial, } \\
\text { Oblique coronal } \\
\text { and sagittal }\end{array}$ \\
\hline TE/TR (ms) & $100 / 3,500$ & $90 / 3,500$ & $90 / 3,600$ & $9 / 550$ & $\begin{array}{l}90 / 3,600 \\
\mathrm{~T} 1=160\end{array}$ & $90 / 3,900$ & $200 / 1,500$ & $10 / 550$ \\
\hline $\mathrm{FOV}(\mathrm{cm})$ & $190-200$ & $190-200$ & $200-240$ & $190-200$ & $190-200$ & $190-200$ & $190-200$ & $190-200$ \\
\hline $\begin{array}{l}\text { Slice thickness } \\
(\mathrm{mm})\end{array}$ & 4 & 4 & 4 & 4 & 4 & 4 & 3 & 3.5 \\
\hline $\begin{array}{l}\text { Interslice gap } \\
(\mathrm{mm})\end{array}$ & 0.5 & 0.5 & 1 & 0.5 & 0.3 & 0.4 & 1.5 & 0.3 \\
\hline No. of slices & 30 & 30 & 25 & 30 & 25 & 30 & 120 & 30 \\
\hline Matrix & $272 \times 215$ & $212 \times 186$ & $256 \times 256$ & $\begin{array}{l}256 \times \\
256\end{array}$ & $252 \times 216$ & $80 \times 79$ & $220 \times 220$ & $256 \times 256$ \\
\hline Flip angle & $90^{\circ}$ & $90^{\circ}$ & $90^{\circ}$ & $90^{\circ}$ & $90^{\circ}$ & $90^{\circ}$ & $90^{\circ}$ & $90^{\circ}$ \\
\hline Echo train length & 19 & 20 & 20 & 4 & 22 & - & 94 & 4 \\
\hline $\begin{array}{l}\text { Diffusion } \\
\text { directions }\end{array}$ & - & - & - & - & - & 3 & - & - \\
\hline$b$-value $\left(\mathrm{s} / \mathrm{mm}^{2}\right)$ & - & - & - & - & - & $\begin{array}{l}50,400 \\
800\end{array}$ & - & - \\
\hline
\end{tabular}

Abbreviations: FS, fat suppressed; SPAIR, spectrally selective adiabatic inversion recovery; STIR, short tau inversion recovery; TI, inversion time; VISTA, 3D volume isotropic turbo spin-echo acquisition.

- Secondary extension of primary tract: Secondary extensions of fistulous tracts detected for horseshoe, intersphincteric, ischioanal/ischiorectal space, supralevator, or translevator extensions.

- Abscess formation: Determine the size, location, and extension of perianal abscess in association with fistula. Early abscess formation is defined as a localized distension of tract more than $5 \mathrm{~mm}$ and which shows DWI restriction and irregular peripheral enhancement on postcontrast images. The presence of air pockets within collection also suggests abscess formation.

- Inflammation without abscess formation: It is defined as an area of increased signal intensities in T2W SPAIR images, no DWI restriction, and showing ill-defined diffuse postcontrast enhancement.

DWI images with $b$-value of $800 \mathrm{smm}^{2}$ were used for visibility comparison with T2W images. The visibility of a perianal fistula was graded on a 3-point scale from 0 to 2 . Score $0=$ no evident fistula, 1 = probably present fistula, and $2=$ distinctly present fistula. ${ }^{12}$ To know the diagnostic performance of DWI in the evaluation of perianal fistula, the imaging findings of the fistula were determined on DWI, T2W, combined T2W-DWI images, and CEMRI. As a reference for grading perianal fistula, the combined T2W-CEMRI (contrast enhanced MR) images were used..$^{15}$

\section{Quantitative Image Analysis}

The ADC values were generated in the operating system console using region of interest (ROI) placed in the fistulous tract. Constant diameter of circular ROI was used with a minimum area of $0.1 \mathrm{~cm}^{2}$. Initially the ROI was placed in the DWI image, after copying the same ROI from DWI image pasted in the ADC map image and then mean ADC value was calculated, as shown in - Figs. 1 and 2. Calculation of mean ADC value was done and $b=50, b=400$, and $b=800 \mathrm{smm}^{2}$ images were obtained and finally mean average of these ADC values was obtained.
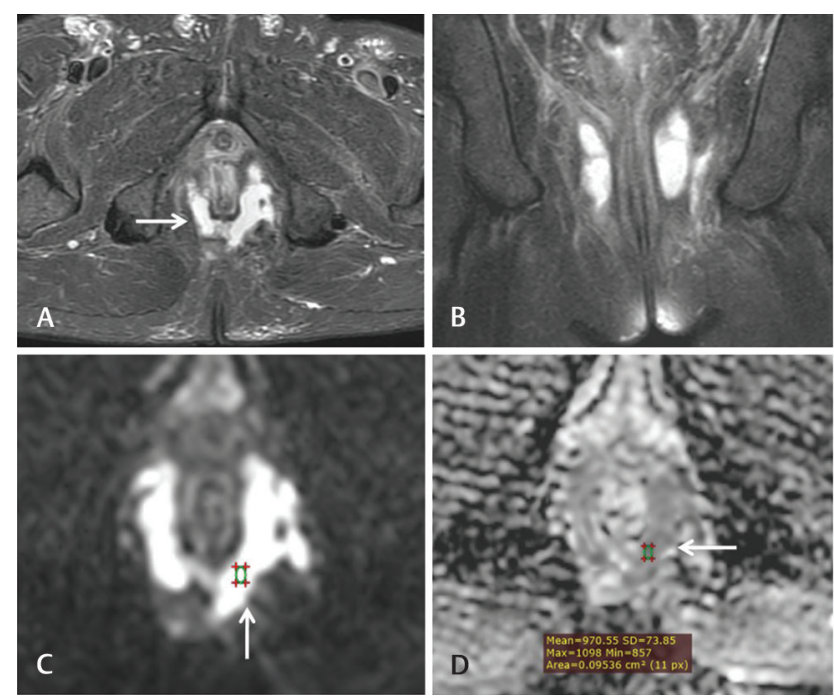

Fig. 1 (A-D): 41-year-old male patient with Grade-4 FIA and multiple external fistulous openings. Axial and coronal T2W SPAIR images ( $A$ and $B$ ) show hyperintense multiple fistulae in the perianal region with communication of these tracts within posterior intersphincteric space and surrounding hyperintense inflammatory changes $(\rightarrow$ arrow). Axial DWI image (C) shows the diffusion restriction in the irregular outlined fistulae $(\leftarrow$ arrow). Axial postcontrast image (D) shows irregular peripheral enhancement of the fistulous tracts with minimal central nonenhancing areas ( $\downarrow$ arrow). 

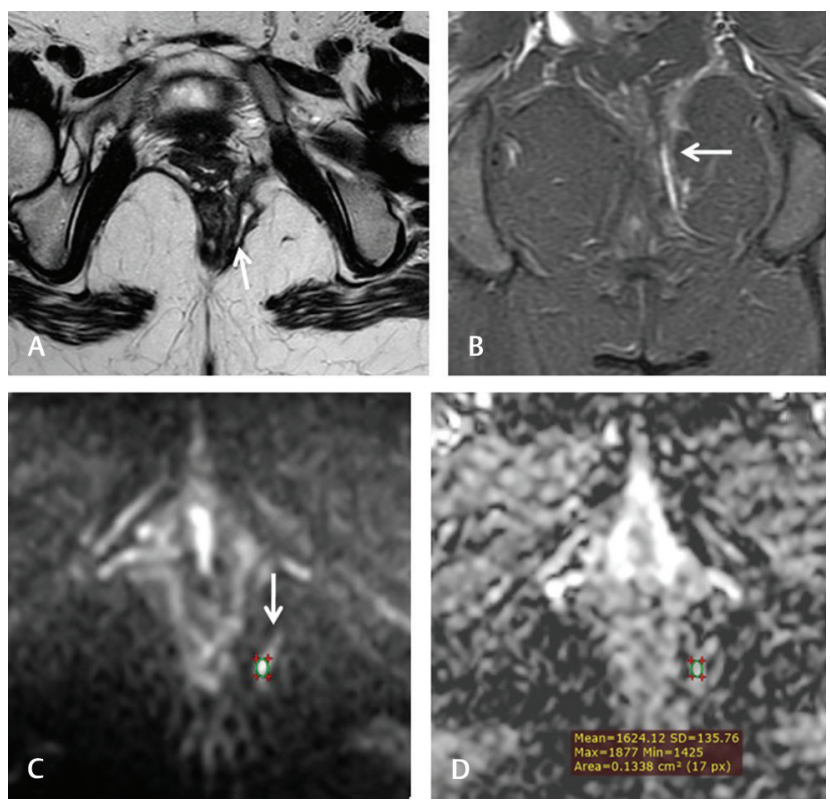

Fig. 2 (A-E): 40-year-old male patient with Grade-3 FIA. Axial and coronal T2W SPAIR images $(A-C)$ show T2 hyperintense (visibility score 2) transsphincteric fistula at 6 O'clock position extends superiorly into posterior intersphincteric space with Y-shaped ramification ( $\rightarrow$ arrow) with minimal surrounding hyperintense inflammatory changes. Axial DWI and ADC images (D and E) show bright signals on DWI (visibility score 2) with peripheral hypointense signal with central hyperintensity on ADC map image ( $\leftarrow$ arrow).

\section{Clinical and Surgical Correlation}

Surgical findings were used as the gold standard for active and inactive fistulas in 28 patients who underwent surgery. Nineteen patients who did not undergo surgery were categorized according to the findings on local clinical examination. On local clinical examination, active fistula was defined as where there was detection of pus and or presence of active signs of inflammation like redness, pain, and swelling around the perianal fistula. The absence of pus or active inflammatory signs around the fistula was categorized as inactive fistula.

\section{Statistical Analysis}

Data were presented in terms of percentage and mean. Calculations were done using Microsoft Excel and SPSS programs (Statistical Package for the Social Science version 16, SPSS Inc., Chicago, United States).

The visibility scores of each of the DWI, T2W, and CEMRI were compared with the combined DWI-T2W images using a Chi-square test. In addition, visibility score of each sequence was also compared between active and inactive fistula groups using a Chi-square test. The mean ADC value of active and inactive perianal fistulas was compared using an independent unpaired $t$-test. Receiver operating characteristic (ROC) curve analysis was performed to determine the optimal cutoff ADC value for differentiating active and inactive fistulae.

\section{Results}

The study included 47 patients, 40 were males and 7 were females. The mean age was $38.5 \pm 1.4$ [standard deviation,
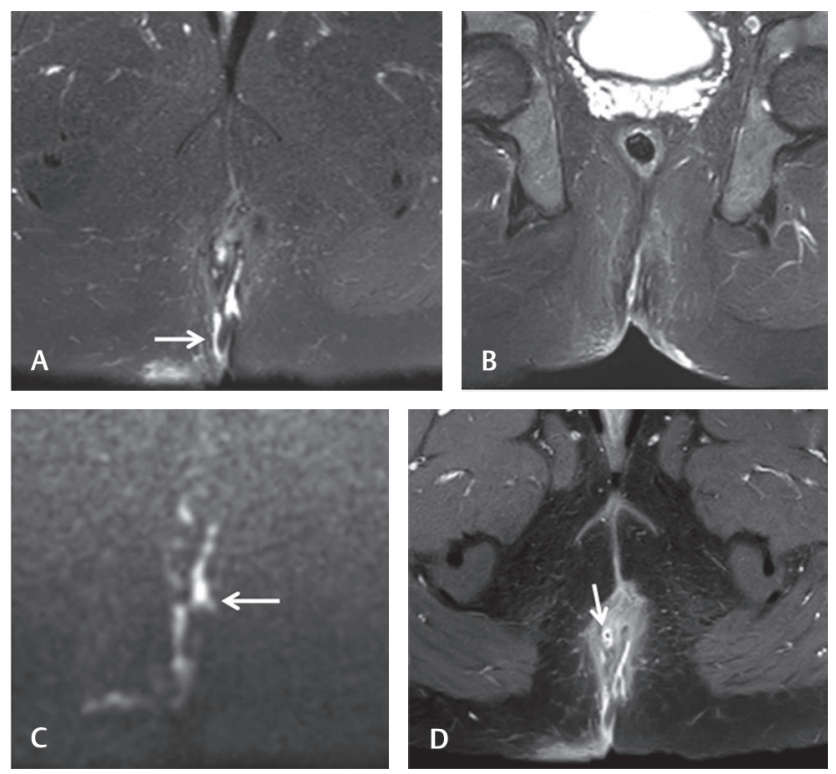

Fig. 3 (A-D): 18-year-old male patient with active Grade-4 FIA. Axial and coronal T2W SPAIR images (A and B) show horseshoe appearing hyperintense fistulae (visibility score 2 ) confined in posterior intersphincteric space ( $\rightarrow$ arrow). Axial DWI (C) image shows horseshoe-appearing fistulous tracts (visibility score 2 ) in both sides of the anal canal with a posterior communication ( $\uparrow$ arrow). Axial $A D C$ image (D) shows the placement of ROI in slightly low signal intensity fistula tract ( $\leftarrow$ arrow) for ADC value calculation.

SD] years. A total of 59 perianal fistulae were detected in 47 patients and 8 patients (17\%) had more than one fistula [-Fig. 3]. Thirty-two patients (68\%) had $n=43$ active perianal fistulas and15 patients (32\%) had $n=16$ inactive fistulas. Twenty-eight patients $(60 \%)$ showed secondary ramification of the primary fistula tract, confined within the intersphincteric space [ - Fig. 4] in 15 patients (31.9\%), ischioanal space/ischiorectal fossa [-Fig. 1] in 9 patients (19.1\%), and supralevator space in 4 patients (8.5\%) [ - Figs. $\mathbf{2}$ and $\mathbf{5}$ ]. Horseshoe-appearing fistula was observed in six patients (12.8\%) [ - Fig. 1]. Perianal fistula associated with abscess was observed in 19 patients (40.4\%), 17 abscesses (36.2\%) within intersphincteric space and 2 abscesses (4.3\%) within ischioanal space/ischiorectal fossa [ - Fig. 5 and 6], according to St James classification, there were 24 grade- 1 fistulas, 14 grade-2 fistulas, 9 grade-3 fistulas [ - Fig. 7], 6 grade- 4 fistulas[ Figs 1,3,4 and 8 , and 6 grade- 5 fistulas [-Figs. 2 and $\mathbf{5}$ ].

\section{DWI, T2W, and CEMRI Visibility of Perianal Fistula}

On evaluating 59 perianal fistulas in 47 patients, 47 perianal fistulas (79.6\%) were distinctly visualized (score 2 ) on DWI [Fig. 9], in comparison to 54 fistulas (91.5\%) on T2W [ - Figs 6], 58 fistulas (98.3\%) on combined DWI-T2W, and 57 fistulas (96.6\%) on CEMRI. Twelve perianal fistulas were poorly visualized (score 1) on DWI [ - Fig. 2], in comparison to 5 fistulas on T2W [ - Fig. 8], 2 inactive fistulas on CEMRI, and 1 fistula on combined DWI-T2W. The visibility scores on DWI were not significantly different from that of T2W $(p$-value $=0.984)$ and both of them were less than the visibility scores of the combined DWI-T2W.The visibility scores of perianal fistulas on DWI were significantly different in active and inactive 
fistulas ( $p$-value $=0.006)$. However, the visibility scores on T2W, CEMRI, and combined DWI-T2W did not show any statistically significant difference between the active and inactive fistulas shown in $\mathbf{- T a b l e} 2$.

\section{Postcontrast Imaging Appearance of Perianal Fistula}

Variable pattern of contrast enhancement elicited in 59 perianal fistulas of 47 patients. Only peripheral postcontrast enhancement without central enhancement of the
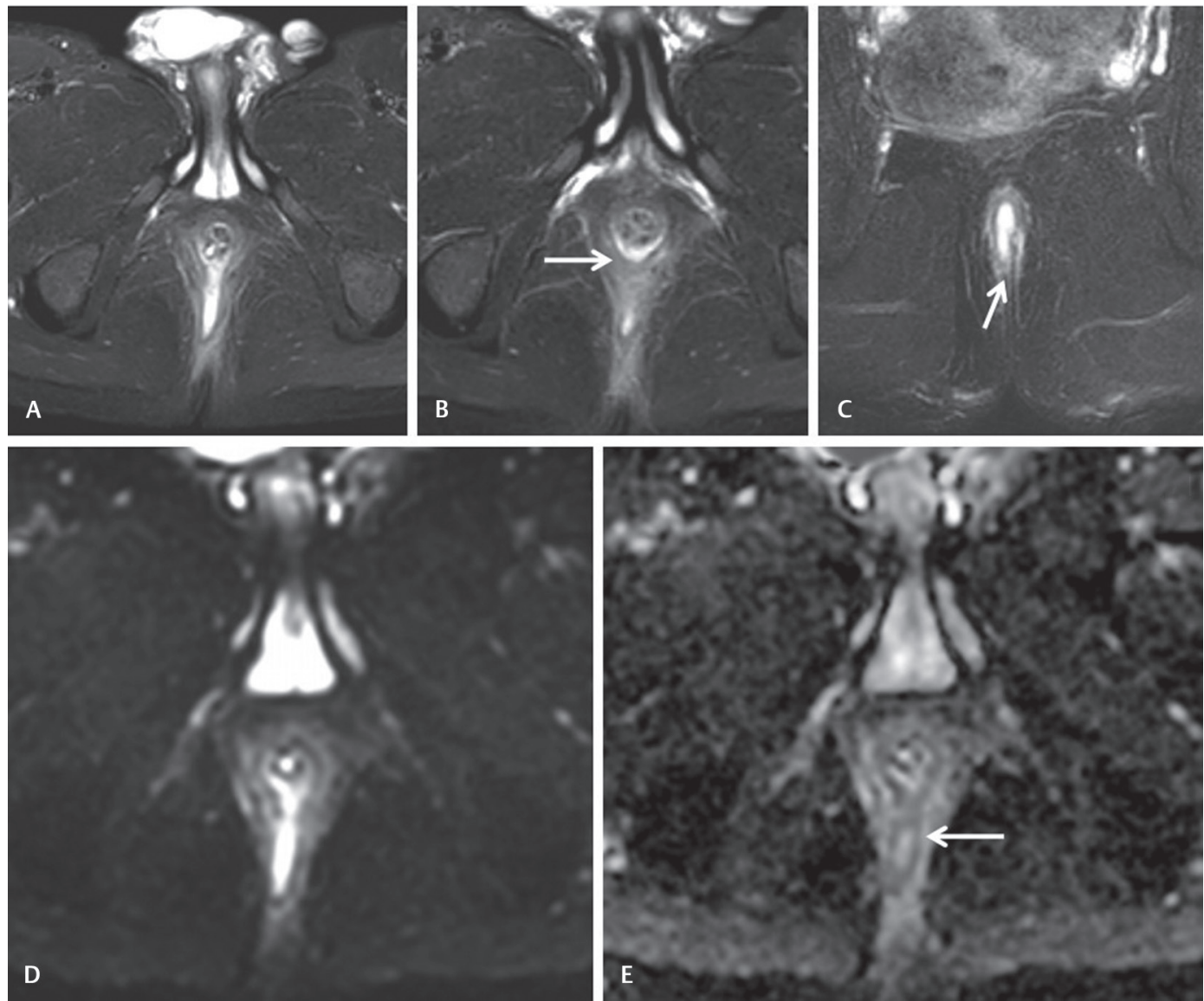

Fig. 4 (A-D): 29-year-old female with inactive Grade-5 FIA. Axial T2WI and coronal T2W SPAIR images (A and B) show a long coursed hyperintense fistulous tract (visibility score 2 ) in the left perineal region at 5 O'clock position in extra-sphincteric location ( $\uparrow$ arrow) and pierced the left levator ani muscle ( $\leftarrow$ arrows). Axial DWI and ADC map images (C and D) show the bright signal on DWI (visibility score 2 ) of the fistula ( $\downarrow$ arrow). ROI placement shown in DWI and ADC map images and calculation obtained from ADC map image.

Table 2 Visibility score of DWI, T2W, CEMRI, and combined T2W-DWI MRI sequences in 59 perianal fistulas in 47 patients

\begin{tabular}{|c|c|c|c|c|c|}
\hline MRI sequence & Visibility score & $\begin{array}{l}\text { Total number } \\
(n=59)\end{array}$ & $\begin{array}{l}\text { Active fistula } \\
(n=43)\end{array}$ & $\begin{array}{l}\text { Inactive fistula } \\
(n=16)\end{array}$ & $p$ (chi-square) \\
\hline \multirow[t]{3}{*}{ DWI } & Score 2 & 47 & 38 & 9 & 0.006 \\
\hline & Score 1 & 12 & 5 & 7 & \\
\hline & Score 0 & 0 & 0 & 0 & \\
\hline \multirow[t]{3}{*}{$\mathrm{T} 2 \mathrm{~W}$} & Score 2 & 54 & 40 & 14 & 0.498 \\
\hline & Score 1 & 5 & 3 & 2 & \\
\hline & Score 0 & 0 & 0 & 0 & \\
\hline Combined & Score 2 & 58 & 43 & 15 & 0.098 \\
\hline \multirow[t]{2}{*}{ DWI-T2W } & Score 1 & 1 & 0 & 1 & \\
\hline & Score 0 & 0 & 0 & 0 & \\
\hline \multirow[t]{3}{*}{ CEMRI } & Score 2 & 57 & 43 & 14 & 0.070 \\
\hline & Score 1 & 2 & 0 & 2 & \\
\hline & Score 0 & 0 & 0 & 0 & \\
\hline
\end{tabular}



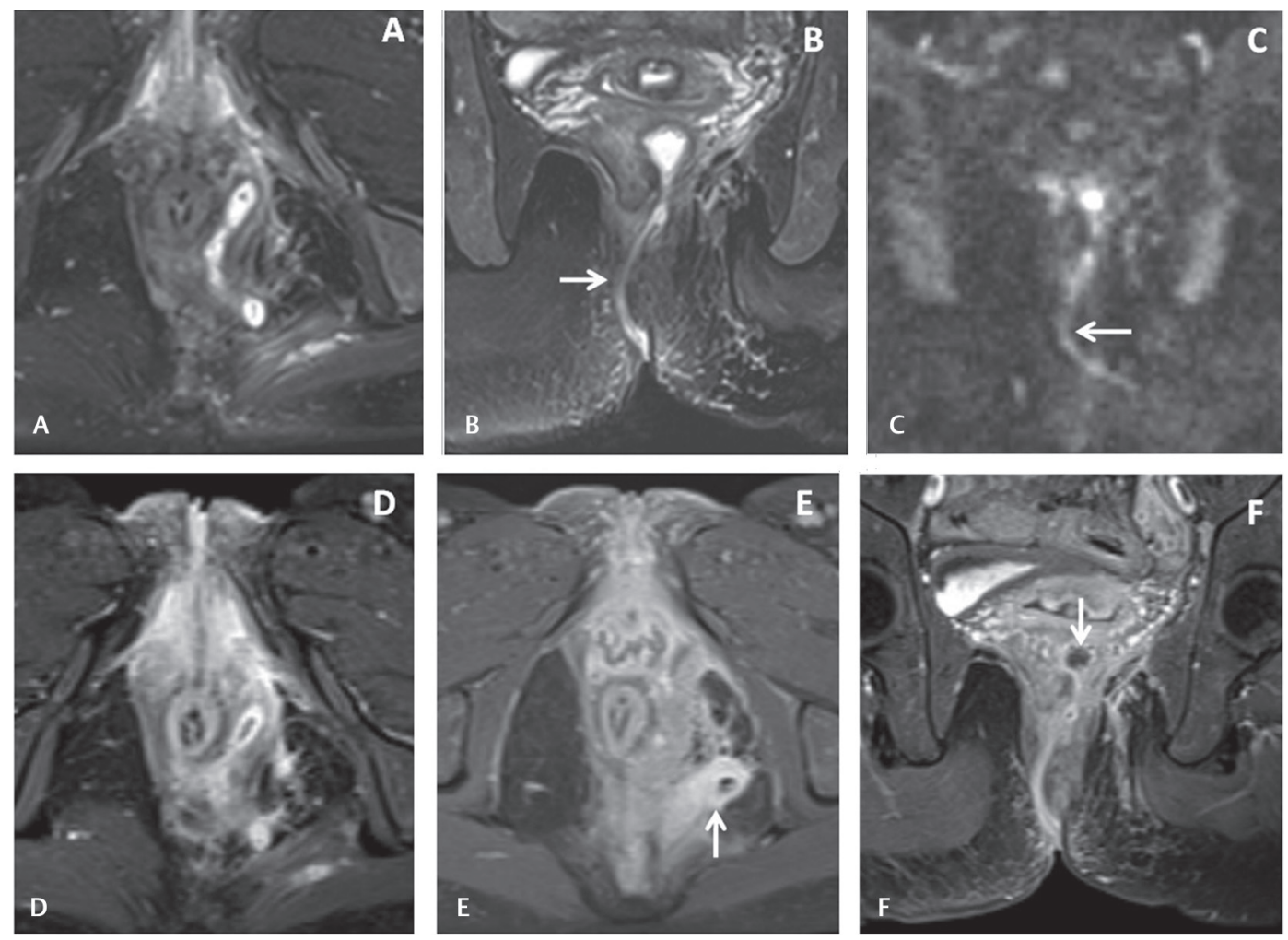

Fig. 5 (A-F): 25-year-old female with Grade-5 FIA. Axial and coronal T2W SPAIR images (A and B) show a curve coursed hyperintense fistula with a supra-levator course ( $\rightarrow$ arrow) piercing the left levator muscle with associated inflammatory changes in left ischiorectal fossa. Coronal DWI image (C) shows the fistulous tract ( $\leftarrow$ arrow). The axial and coronal postcontrast images (D-F) shows the irregular enhancement of the fistula with thick-walled abscess formation in left ischiorectal fossa ( $\uparrow$ arrow) and left pararectal space ( $\downarrow$ arrow).

fistulous tract representing fluid-filled tract was observed in 24 fistulas (40.7\%) [ - Figs. 5, 6, and 10], central enhancement of the tract with high signal on T2WI representing granulation tissue in 28fistulas (47.5\%)\% [ - Fig. 3], and minimal progressive enhancement of the tract with low signal on T2WI images representing fibrosis or healing in 7 (11.9\%).

\section{ADC values of Perianal Fistula}

ROI placement within the perianal fistula is shown in -Figs. 1 and $\mathbf{2}$ for active and inactive fistulas. The mean of ADC values of active perianal fistula was $0.972 \pm 0.127$ [SD] $10^{-3} \mathrm{~mm}^{2} / \mathrm{s}$ and that of inactive fistula was $1.232 \pm 0.185$ [SD] $10^{-3} \mathrm{~mm}^{2} / \mathrm{s}$. There was a statistical significant difference ( $p$-value $<0.0005$ ) between the mean ADC values of active and inactive fistulas while using unpaired student $t$-test. Boxplot of mean ADC values of active and inactive fistulae shows a considerable overlap between these two groups. Despite this overlap there was a statistically significant difference between the mean of ADC values of active and inactive fistulae with $p$-value of 0.0005 [ - Fig. 11].

ROC curve analysis of mean ADC value of perianal fistulae in our study sample showed cutoff mean ADC value of 1.105 $\times 10^{-3} \mathrm{~mm}^{2} / \mathrm{s}$ used for differentiating active from the inactive fistula with a sensitivity of $87.5 \%$, a specificity of $73.3 \%$, a positive predictive value of $87.5 \%$, a negative predictive value of $73.3 \%$, and a diagnostic accuracy of $82.98 \%$ [ - Fig. 12].
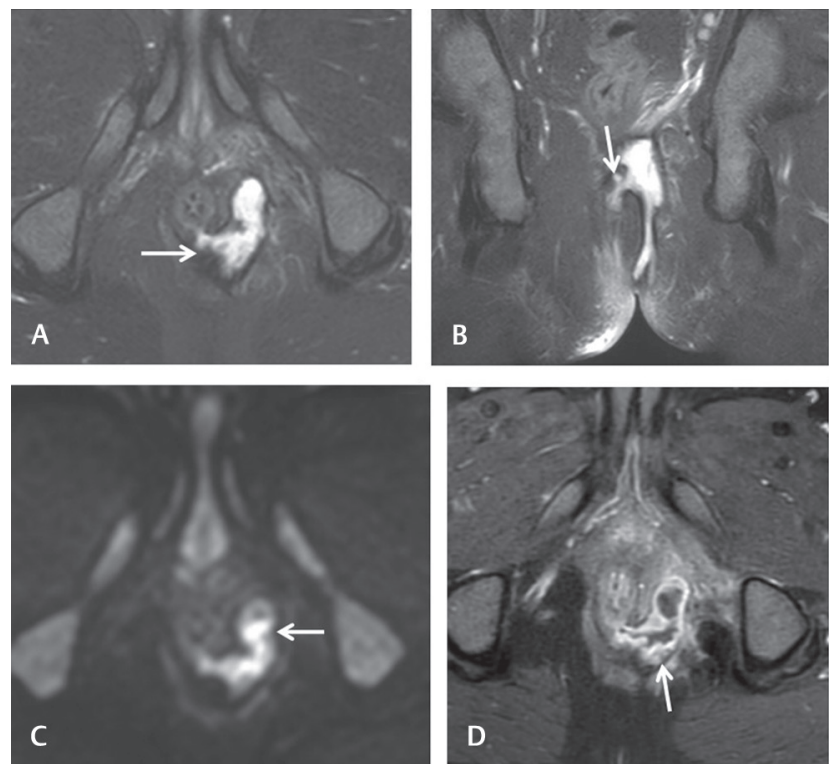

Fig. 6 (A-D): 33-year-old male with Grade-IV FIA. Axial and coronal T2W SPAIR images (A and B) show extra-sphincteric fistulous tract $(\leftarrow$ arrow) in the left perineal region with a medially coursed transsphincteric ramification ( $\downarrow$ arrow) and open into anal canal. Axial DWI map image (C) shows the bright signal (visibility score 2 ) of the tract $(\leftarrow$ arrow). Axial postcontrast image (D) shows irregular peripheral enhancement of the fistula ( $\uparrow$ arrow) with nearby abscess formation and inflammatory changes in left ischiorectal fossa. 

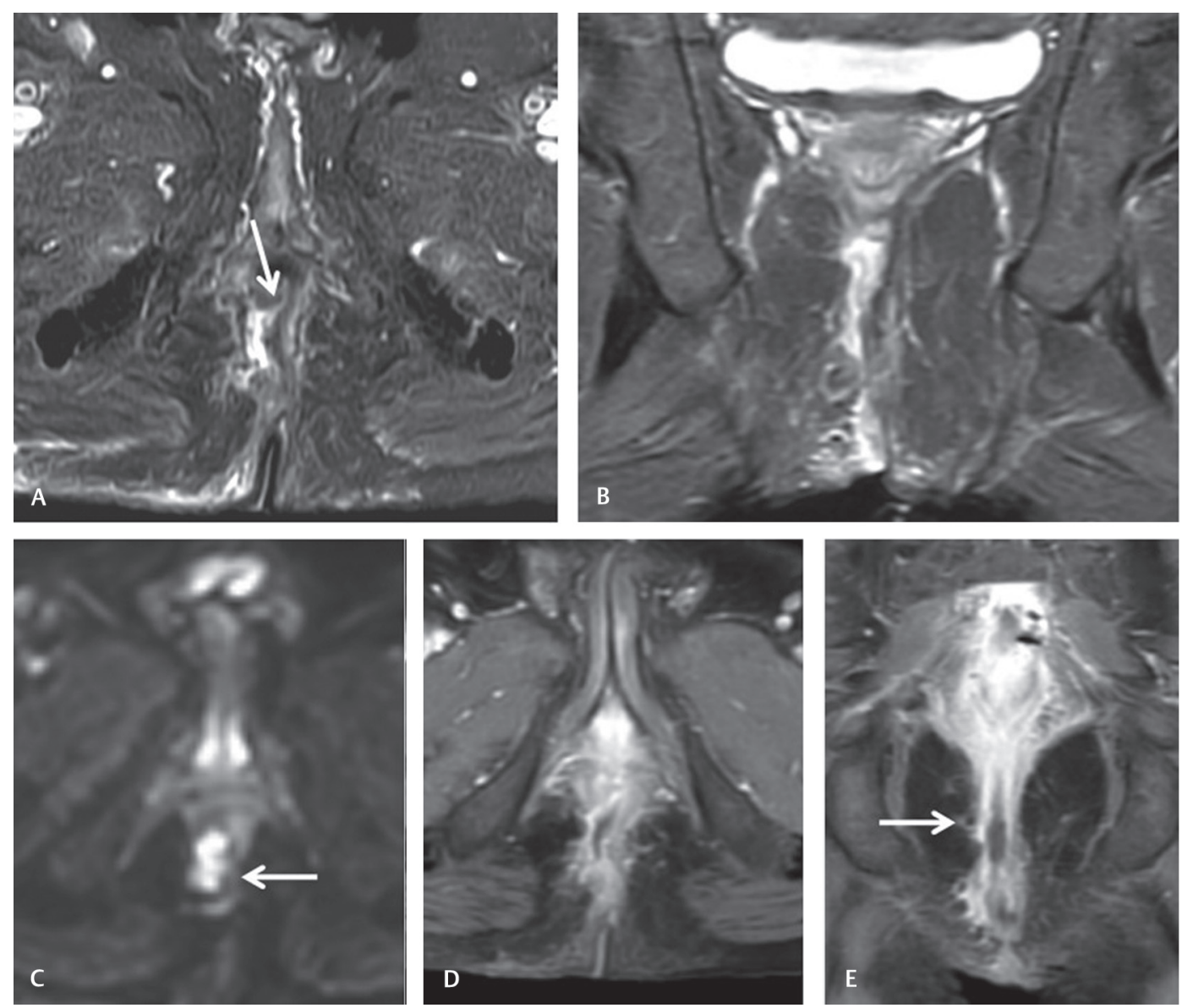

Fig. 7 73-year-old male patient with Grade-3 FIA. Axial and coronal T2W SPAIR images (A, B) show transsphincteric fistula at 7 O'clock position with transsphincteric defect ( $\downarrow$ arrow). Axial DWI image $(\mathbf{C})$ shows diffusion restriction of the fistula ( $\leftarrow$ arrow). Axial and coronal postcontrast images $(\mathbf{D}, \mathbf{E})$ show irregular peripheral enhancement in the fistula with central fluid filled tract and surrounding inflammation.

\section{Discussion}

Surgical excision of perianal fistulous tracts and drainage of associated abscess with preservation of anal sphincteric complex is the primary surgical treatment. ${ }^{5,16}$ Fistula recurrence after surgery occurs usually due to untreated or undetected fistula and abscess at the time of surgery. ${ }^{17}$ Hence preoperative MRI evaluation of perianal fistula is essential to avoid treatment failure after surgery.

Various MRI sequences, especially combined DWI-T2W images, can identify the fistulous tract in relation to the anal sphincteric complexes, their course, ramifications, or associated abscesses. ${ }^{3}$

In our study sample, the visibility scores of the combined DWI-T2W images overcome the visibility score on DWI, T2W and CEMRI images shown in - Table 2.The findings of our study sample are comparable with the previous study conducted by Mohsen and Osman. ${ }^{12}$

The concordance rate between preoperative MRI and surgical findings varies from 86 to $88 \%$ in previous studies. ${ }^{5,18}$ However, recent literature showed more sensitivity of MRI with a reported accuracy of $97 \%, 19$ and considered it the most accurate preoperative technique for classification of the perianal fistulae. $^{5}$
Grade 1 and Grade 2 perianal fistulae were associated with a satisfactory outcome after initial surgery, whereas Grades 3 to 5 were usually associated with unsatisfactory outcome after initial surgery and these patients are more prone to recurrence and need further surgery. ${ }^{6}$

In our study sample, Grade 1 perianal fistulas were most commonly observed in $40.7 \%$, followed by grade 2 fistulas in $23.7 \%$. Khera et $\mathrm{al}^{20}$ found the most common intersphincteric type of perianal fistula in $60 \%$, followed by transsphincteric in $33 \%$. Morris et $\mathrm{al}^{21}$ found intersphincteric fistula in $70 \%$ while transsphincteric in $20 \%$. de Miguel Criado et $\mathrm{al}^{3}$ commonly found Grade 3 and Grade 4 fistulae in their study sample of 178 patients. The findings of our study sample were compared with the previous literature shown in - Table 3.

DWI had a potential role in assessing the activity of the perianal fistulas. ${ }^{8,9,15,21}$ In our study, the mean of ADC value of active and inactive perianal fistulas and their cutoff mean ADC values are comparable with those of the study conducted by Yoshizako et $\mathrm{al}^{8}$ and are shown in - Table 3 .

Combined DWI-T2W images may obviate the contrast MRI scan for perianal fistula evaluation, which was compared in our study sample. Almost equivalent performance of CEMRI on visibility of perianal fistula was found as compared with 

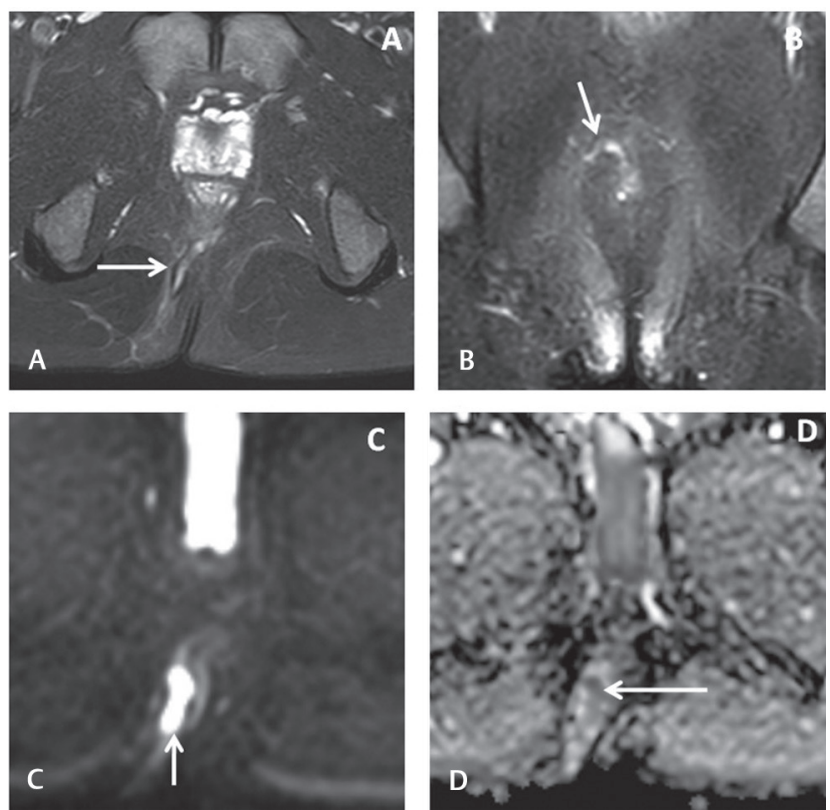

Fig. 8 (A-D): 27-year-oldmale patient with Grade-4 FIA. Axial T2W SPAIR image (A) shows central hyperintense transsphincteric fistula (visibility score 1 ) in perineal region at 7 O'clock position ( $\rightarrow$ arrow). Coronal T2W SPAIR image (B) shows the curve transsphincteric opening of the fistula with sphincteric defect ( $\downarrow$ arrow) and minimal surrounding inflammation. Axial DWI and ADC map images (C and D) show diffusion restriction ( $\uparrow$ arrow) within the tract (visibility score 2 ) with low ADC value ( $\leftarrow$ arrow).
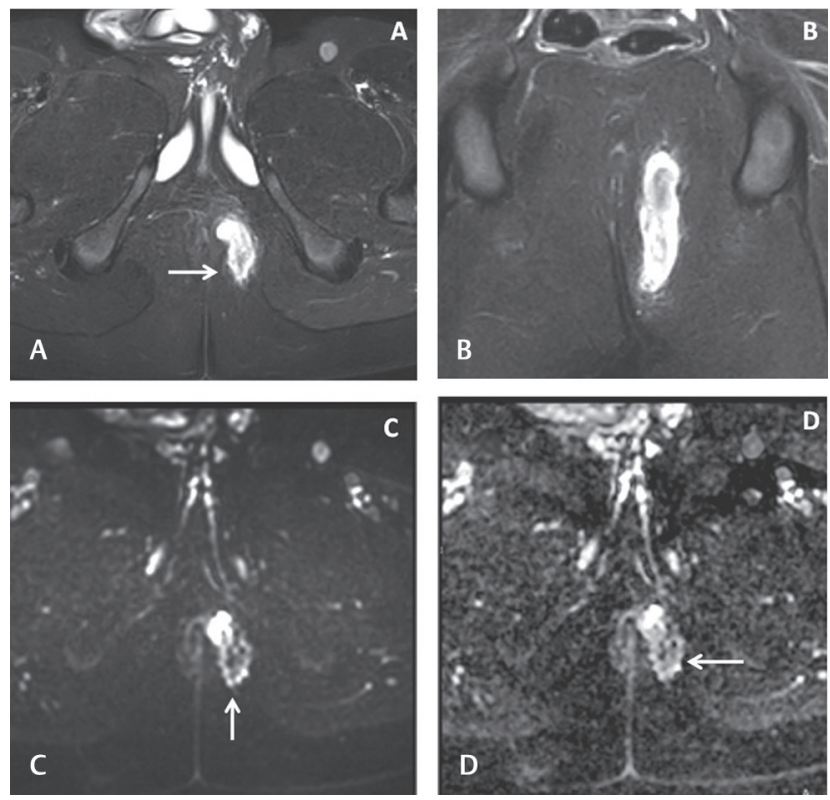

Fig. 9 (A-D): 15-year-old male patient with Grade-4 FIA. Axial and coronal T2W SPAIR images (A and B) show hyperintense fistula in the left perineal region at the 5 O'clock position ( $\rightarrow$ arrow) with hyperintense minimal surrounding inflammation. Axial DWI and ADC map images ( $C$ and $D)$ show bright signals on DWI ( $\uparrow$ arrow) with variable signal intensities on ADC map image ( $\leftarrow$ arrow).
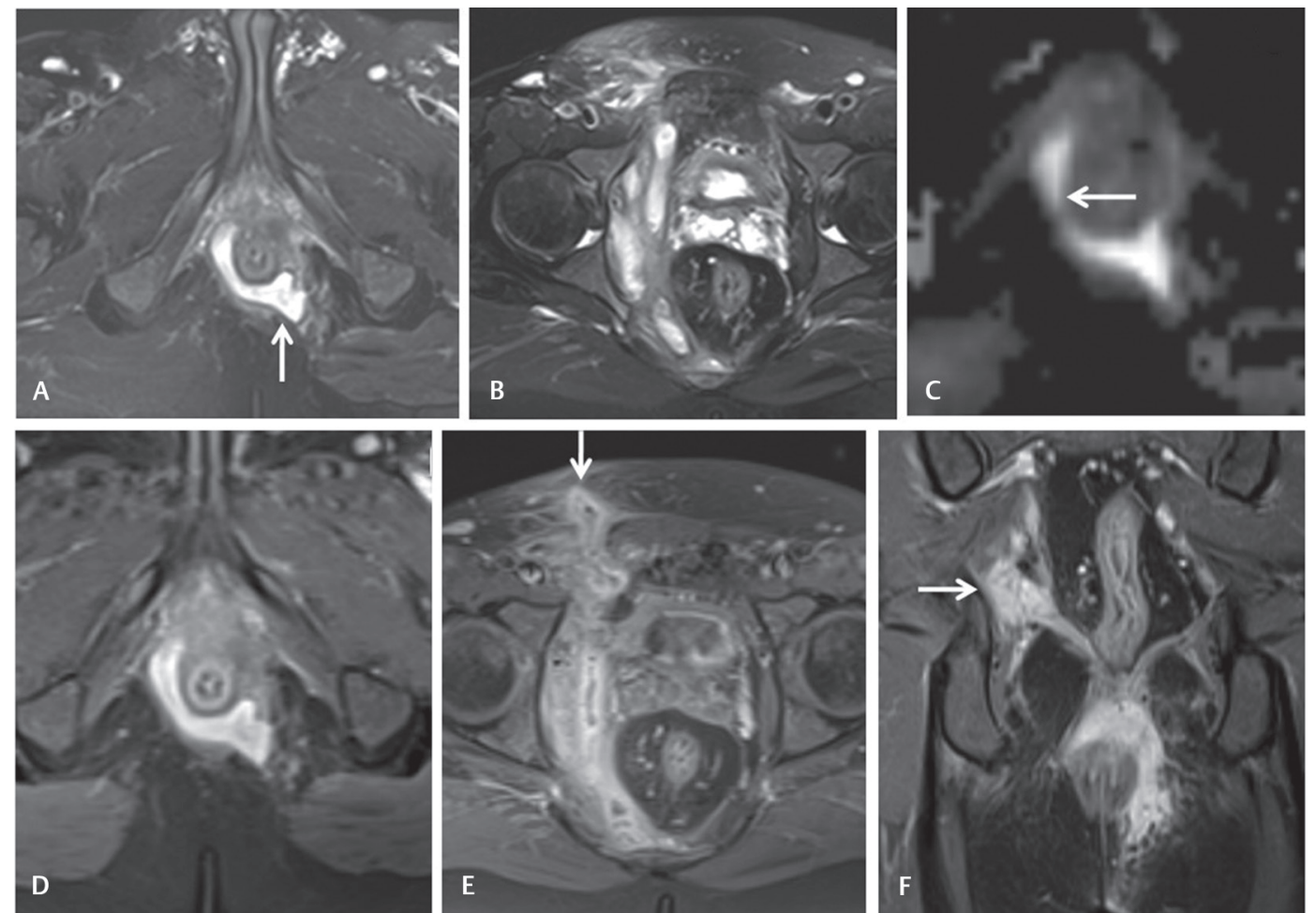

Fig. 10 (A-F): 35-year-old male with Grade-5 FIA. Axial T2W SPAIR images (A and B) show hyperintense transsphincteric fistula at 5 O'clock position with partial horseshoe ramification ( $\uparrow$ arrow). Axial DWI image (C) shows diffusion restriction of the fistula tract ( $\leftarrow$ arrow). The axial and coronal postcontrast images (D-F) show the irregular enhancement of the fistulae with central liquefaction. Supralevator extension of fistula identified ( $\rightarrow$ arrow) with extension of fistula along the right para-prostatic and para-vesicular spaces which finally open into the anterior abdominal wall ( $\downarrow$ arrow). 
Table 3 Literature review of MRI findings of perianal fistula

\begin{tabular}{|c|c|c|c|c|c|}
\hline \multirow{2}{*}{$\begin{array}{l}\text { Parameters } \\
\begin{array}{l}\text { Total number of } \\
\text { patients }\end{array}\end{array}$} & \multirow{2}{*}{$\begin{array}{l}\text { Yoshizako et al }{ }^{8} \\
n=24 \text { with } 41 \text { fistulae }\end{array}$} & \multicolumn{2}{|c|}{$\begin{array}{l}\text { Mohsen and Osman, }{ }^{12} \text { de } \\
\text { Miguel Criado et } \text { al }^{3}\end{array}$} & \multirow{2}{*}{$\begin{array}{l}\text { Wang et } \text { al }^{14} \\
n=34\end{array}$} & \multirow{2}{*}{$\begin{array}{c}\text { Present study } \\
n=47 \text { with } 59 \text { fistulae }\end{array}$} \\
\hline & & $\begin{array}{l}n=38 \text { with } 45 \\
\text { fistulae }\end{array}$ & $n=178$ & & \\
\hline $\begin{array}{l}\text { Classification of } \\
\text { perianal }\end{array}$ & $\begin{array}{l}\text { Intersphincteric, } n=27 \\
(65.8 \%)\end{array}$ & $\begin{array}{l}\text { Grade- } 1=21 \\
(46.67 \%)\end{array}$ & $\begin{array}{l}\text { Grade-1 = } 44 \\
(24.7 \%)\end{array}$ & $\begin{array}{l}\text { Intersphincteric, } n=19 \\
(55.9 \%)\end{array}$ & Grade-1 = 24 (40.7\%) \\
\hline \multirow{4}{*}{$\begin{array}{l}\text { Fistula St James's } \\
\text { University Or Parks } \\
\text { system }\end{array}$} & & $\begin{array}{l}\text { Grade-2 = } 4 \\
(8.8 \%)\end{array}$ & $\begin{array}{l}\text { Grade-2 = } 33 \\
(18.5 \%)\end{array}$ & & Grade-2 = 14 (23.7\%) \\
\hline & $\begin{array}{l}\text { Transsphincteric, } n=6 \\
(14.6 \%)\end{array}$ & $\begin{array}{l}\text { Grade-3 = } 4 \\
(8.8 \%)\end{array}$ & $\begin{array}{l}\text { Grade-3= } \\
(24.2 \%)\end{array}$ & $\begin{array}{l}\text { Transsphincteric, } n=9 \\
(26.5 \%)\end{array}$ & Grade-3 = 9 (15.2\%) \\
\hline & $\begin{array}{l}\text { Suprasphincteric, } n=4 \\
(9.75 \%)\end{array}$ & $\begin{array}{l}\text { Grade- } 4=5 \\
(11.1 \%)\end{array}$ & $\begin{array}{l}\text { Grade- } 4=45 \\
(25.3 \%)\end{array}$ & $\begin{array}{l}\text { Suprasphincteric, } n=4 \\
(11.8 \%)\end{array}$ & Grade-4 = 6 (10.2\%) \\
\hline & $\begin{array}{l}\text { Extrasphincteric, } n=4 \\
(9.75 \%)\end{array}$ & $\begin{array}{l}\text { Grade- } 5= \\
6(13.3 \%) \\
\text { Extrasphincteric, } \\
n=5(11.1 \%)\end{array}$ & $\begin{array}{l}\text { Grade- } 5=13 \\
(7.3 \%)\end{array}$ & $\begin{array}{l}\text { Extrasphincteric, } n=2 \\
(5.9 \%)\end{array}$ & Grade-5 = 6 (10.2\%) \\
\hline $\begin{array}{l}\text { Mean ADC value of } \\
\text { active fistula }\end{array}$ & $\begin{array}{l}0.908 \pm 0.171[\mathrm{SD}] \mathrm{x} \\
10^{-3} \mathrm{~mm}^{2} / \mathrm{s}\end{array}$ & $\begin{array}{l}1.3 \pm 0.5[\mathrm{SD}] \mathrm{x} \\
10^{-3} \mathrm{~mm}^{2} / \mathrm{s}\end{array}$ & - & $\begin{array}{l}0.979 \pm 0.441[\mathrm{SD}] \times 10^{-3} \\
\mathrm{~mm}^{2} / \mathrm{s}\end{array}$ & $\begin{array}{l}0.972 \pm 0.127[\mathrm{SD}] \mathrm{x} \\
10^{-3} \mathrm{~mm}^{2} / \mathrm{s}\end{array}$ \\
\hline $\begin{array}{l}\text { Mean ADC value } \\
\text { of active perianal } \\
\text { fistula tract }\end{array}$ & & $10^{-3} \mathrm{~mm}^{2} / \mathrm{s}$ & & & $10^{-3} \mathrm{~mm}^{2} / \mathrm{s}$ \\
\hline $\begin{array}{l}\text { Mean ADC value of } \\
\text { inactive fistula }\end{array}$ & $\begin{array}{l}1.124 \pm 0.244[\mathrm{SD}] \times \\
10^{-3} \mathrm{~mm}^{2} / \mathrm{s}\end{array}$ & $\begin{array}{l}1.43 \pm 0.4[\mathrm{SD}] \\
\times 10^{-3} \mathrm{~mm}^{2} / \mathrm{s}\end{array}$ & - & $\begin{array}{l}1.393 \pm 0.256[\mathrm{SD}] \times 10^{-3} \\
\mathrm{~mm}^{2} / \mathrm{s}\end{array}$ & $\begin{array}{l}1.232 \pm 0.185[\mathrm{SD}] \mathrm{x} \\
10^{-3} \mathrm{~mm}^{2} / \mathrm{s}\end{array}$ \\
\hline \multirow{2}{*}{$\begin{array}{l}\text { Sensitivity and } \\
\text { specificity of cut-off } \\
\text { ADC value in distin- } \\
\text { guishing active from } \\
\text { inactive fistula }\end{array}$} & $\begin{array}{l}\text { Cut-off ADC }=1.109 \\
\times 10^{-3} \mathrm{~mm}^{2} / \mathrm{s} \text { having } \\
\text { sensitivity }=95.7 \%\end{array}$ & - & - & $\begin{array}{l}\text { Cut-off ADC }=1.069 \times \\
10^{-3} \mathrm{~mm}^{2} / \mathrm{s} \text { having sensi- } \\
\text { tivity }=100 \%\end{array}$ & $\begin{array}{l}\text { Cut-off ADC }=1.105 \\
\times 10^{-3} \mathrm{~mm}^{2} / \mathrm{s} \text { having } \\
\text { sensitivity }=87.5 \%\end{array}$ \\
\hline & Specificity = 50\% & & & Specificity $=57.14 \%$ & Specificity $=73.3 \%$ \\
\hline
\end{tabular}

Abbreviations: ADC, apparent diffusion coefficient; MRI, magnetic resonance imaging; SD, standard deviation.

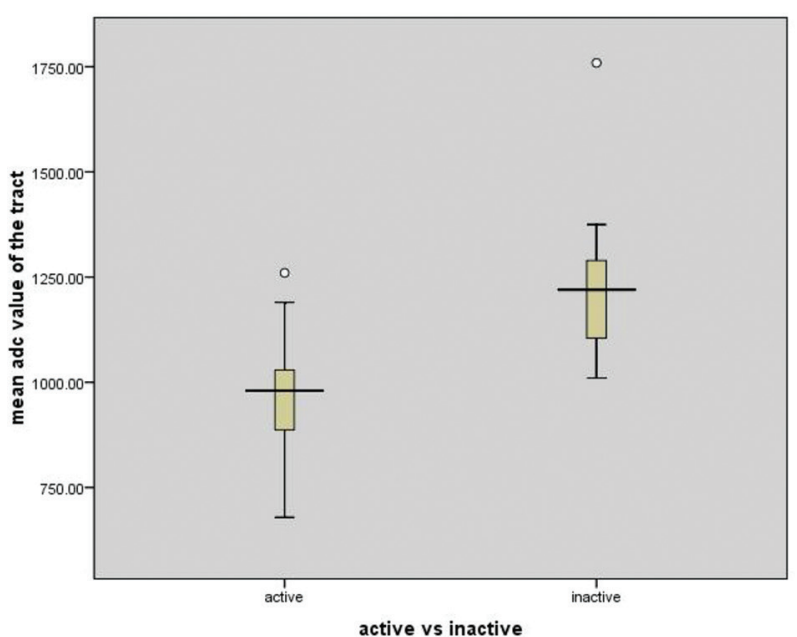

Fig. 11 Boxplot summarizing the range of distribution of the mean ADC values of active and inactive Perianal fistulae in 47 patients. Boxplot of mean ADC value of active and inactive fistulae shows a considerable overlap between these two groups. Despite this overlap there was a statistically significant difference between the mean of $A D C$ value of active and inactive fistulae with a $p$-value of 0.0005 . the combined DWI-T2W images. So, those patients of known contraindication for MR contrast agent, DWI, T2W, and combined DWI-T2W images play an important role. ${ }^{22}$

\section{Conclusion}

DWI alone is not superior to the T2W regarding the visibility of perianal fistula in our study. However, the best performance was observed for combined DWI-T2W image evaluation, although it was not statistically significant than DWI or T2W alone. Mean ADC value calculation with obtained cutoff ADC value helps in differentiating active from the inactive perianal fistulas. We still need a larger study sample to confirm the visibility of perianal fistulas with DWI, T2W, CEMRI, and combined DWI-T2W.

\section{Declaration of Patient Consent}

The authors certify that they have obtained all appropriate patient consent forms. In the form the patient(s) has/have given his/her/their consent for his/her/their images and other clinical information to be reported in the journal. The patients understand that their names and initials will 


\section{ROC Curve}

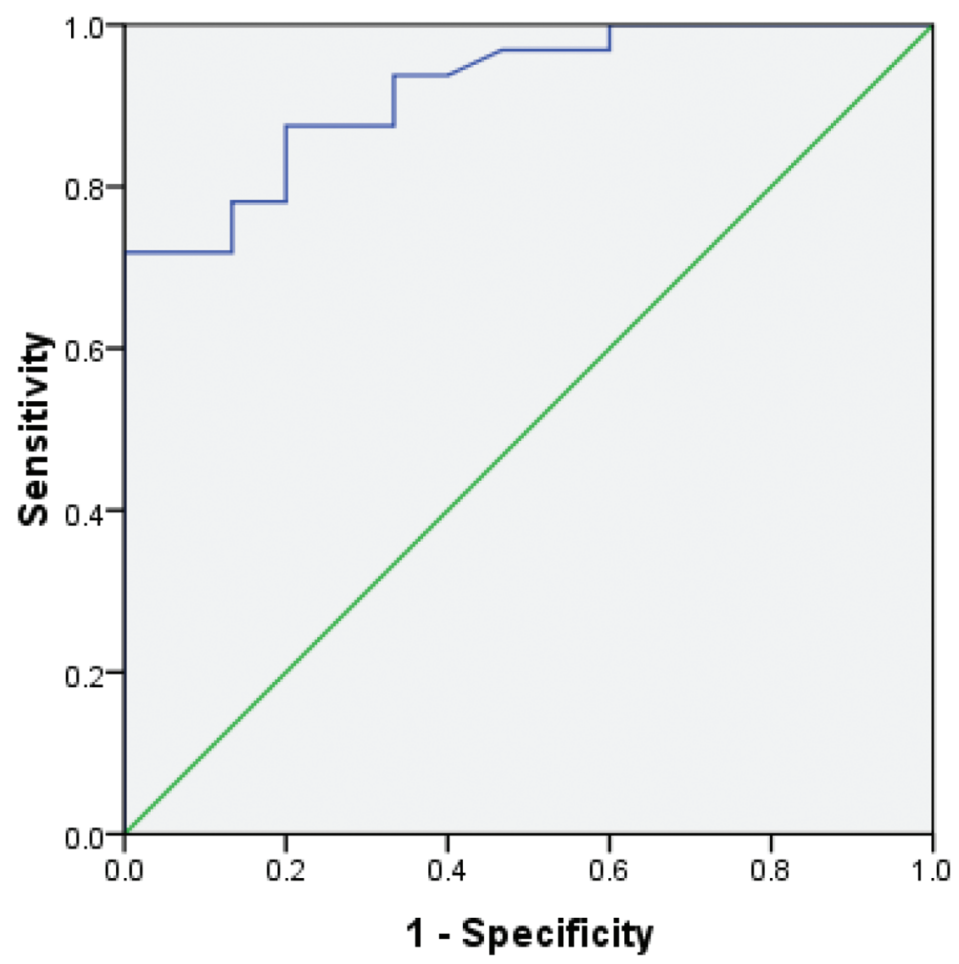

\begin{tabular}{|l|l|l|}
\hline $\begin{array}{l}\text { Criteria (Cut off ADC } \\
\text { value) }\end{array}$ & Sensitivity(\%) & Specificity(\%) \\
\hline$\leq 0.998$ & 65.6 & 100 \\
\hline$\leq 1.105$ & 87.5 & 73.3 \\
\hline$\leq 1.166$ & 90.6 & 66.7 \\
\hline
\end{tabular}

Fig. 12 Receiver operating characteristic (ROC) curve of mean ADC value for perianal fistulae in 47 patients. The cut-off mean ADC value was $1.105 \times 10^{-3} \mathrm{~mm}^{2} / \mathrm{s}$ used for differentiating active from inactive fistula with a sensitivity of $87.5 \%$, specificity of $73.3 \%$, positive predictive value of $87.5 \%$, negative predictive value of $73.3 \%$, and a diagnostic accuracy of $82.98 \%$.

not be published and due efforts will be made to conceal their identity, but anonymity cannot be guaranteed.

\section{Financial Support and Sponsorship}

Nil.

\section{Conflicts of Interest}

There are no conflicts of interest.

\section{References}

1 Zanotti C, Martinez-Puente C, Pascual I, Pascual M, Herreros D, García-Olmo D. An assessment of the incidence of fistula-in-ano in four countries of the European Union. Int J Colorectal Dis 2007;22(12):1459-1462
2 Alabiso ME, Iasiello F, Pellino G, et al. 3D-EAUS and MRI in the activity of anal fistulas in Crohn's disease. Gastroenterol Res Pract 2016;2016:1895694

3 de Miguel Criado J, del Salto LG, Rivas PF, et al. MR imaging evaluation of perianal fistulas: spectrum of imaging features. Radiographics 2012;32(1):175-194

4 George U, Sahota A, Rathore S. MRI in evaluation of perianal fistula. J Med Imaging Radiat Oncol 2011;55(4):391-400

5 Halligan S, Stoker J. Imaging of fistula in ano. Radiology 2006;239(1):18-33

6 Buchanan GN, Halligan S, Bartram CI, Williams AB, Tarroni D, Cohen CR. Clinical examination, endosonography, and MR imaging in preoperative assessment of fistula in ano: comparison with outcome-based reference standard. Radiology 2004;233(3):674-681 
7 Buchanan G, Halligan S, Williams A, et al. Effect of MRI on clinical outcome of recurrent fistula-in-ano. Lancet 2002;360(9346) :1661-1662

8 Yoshizako T, Wada A, Takahara T, et al. Diffusion-weighted MRI for evaluating perianal fistula activity: feasibility study. Eur J Radiol 2012;81(9):2049-2053

9 Hori M, Oto A, Orrin S, Suzuki K, Baron RL. Diffusion-weighted MRI: a new tool for the diagnosis of fistula in ano. J Magn Reson Imaging 2009;30(5):1021-1026

10 Dohan A, Eveno C, Oprea R, et al. Diffusion-weighted MR imaging for the diagnosis of abscess complicating fistula-in-ano: preliminary experience. Eur Radiol 2014;24(11):2906-2915

11 Tomar V, Yadav A, Rathore RK, et al. Apparent diffusion coefficient with higher b-value correlates better with viable cell count quantified from the cavity of brain abscess. AJNR Am J Neuroradiol 2011;32(11):2120-2125

12 Mohsen LA, Osman NM. Diffusion-weighted imaging in the evaluation of perianal fistula and abscess. Egypt J Radiol Nucl Med 2020;51:71

13 Cavusoglu M, Duran S, Sözmen Cllız D, et al. Added value of diffusion-weighted magnetic resonance imaging for the diagnosis of perianal fistula. Diagn Interv Imaging 2017;98(5):401-408

14 Wang Y, Gu C, Huo Y, et al. Diffusion tensor imaging for evaluating perianal fistula: feasibility study. Medicine (Baltimore) 2018;97(29):e11570
15 Bakan S, Olgun DC, Kandemirli SG, et al. Perianal fistula with and without abscess: assessment of fistula activity using diffusion-weighted magnetic resonance imaging. Iran J Radiol 2015;12(4):e29084

16 Berman L, Israel GM, McCarthy SM, Weinreb JC, Longo WE. Utility of magnetic resonance imaging in anorectal disease. World J Gastroenterol 2007;13(23):3153-3158

17 Panes J, Bouhnik Y, Reinisch W, et al. Imaging techniques for assessment of inflammatory bowel disease: joint ECCO and ESGAR evidence-based consensus guidelines. J Crohn's Colitis 2013;7(7):556-585

18 Maccioni F, Colaiacomo MC, Stasolla A, Manganaro L, Izzo L, Marini M. Value of MRI performed with phased-array coil in the diagnosis and pre-operative classification of perianal and anal fistulas. Radiol Med (Torino) 2002;104(1-2):58-67

19 Beets-Tan RG, Beets GL, van der Hoop AG, et al. Preoperative MR imaging of anal fistulas: does it really help the surgeon? Radiology 2001;218(1):75-84

20 Khera PS, Badawi HA, Afifi AH. MRI in perianal fistulae. Indian J Radiol Imaging 2010;20(1):53-57

21 Yoshizako T, Kitagaki H. A pictorial review of the impact of adding diffusion-weighted MR imaging to other MR sequences for assessment of anal fistulae. Jpn J Radiol 2013;31(6):371-376

22 Morris J, Spencer JA, Ambrose NS. MR imaging classification of perianal fistulas and its implications for patient management. Radiographics 2000;20(3):623-635, discussion 635-637 